\section{ECONOMICS}

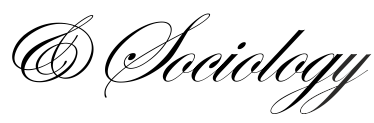

Lyeonov, S., Bilan, S., Yarovenko, H., Ostasz, G., \& Kolotilina, O. (2021). Country's health profile: Social, economic, behavioral and healthcare determinants. Economics and Sociology, 14(3), 322-340. doi:10.14254/2071789X.2021/14-3/17

\title{
COUNTRY'S HEALTH PROFILE: SOCIAL, ECONOMIC, BEHAVIORAL AND HEALTHCARE DETERMINANTS
}

\author{
Serhiy Lyeonov \\ Department of Economic \\ Cybernetics, \\ Sumy State University, Ukraine \\ E-mail: \\ s.lieonov@uabs.sumdu.edu.ua \\ ORCID 0000-0001-5639-3008
}

\section{Svitlana Bilan}

Faculty of Management, Rzeszow University of Technology, Poland

E-mail:s.bilan@prz.edu.pl

ORCID 0000-0001-9814-5459

\section{Hanna Yarovenko}

Department of Economic

Cybernetics,

Sumy State University, Ukraine

E-amil:

a.yarovenko@uabs.sumdu.edu.ua ORCID 0000-0002-8760-6835

\section{Grzegorz Ostasz}

Faculty of Management, Rzeszow University of Technology, Poland

E-amil: gost@ppr.edu.pl

ORCID 0000-0002-7785-9302

\section{Olena Kolotilina}

Department of Economic

Cybernetics,

Sumy State University, Ukraine

e-mail:

o.kolotilina@uabs.sumdu.edu.ua

ORCID 0000-0002-8928-0859

Received: March, 2021

1st Revision: August, 2021

Accepted: September, 2021
ABSTRACT. The article uses the estimation method of the center of mass to model the country's health profile as an indicator for determining the prerequisites for the country's readiness to combat and prevent mass diseases. The authors identified the most relevant determinants that characterized society's social, economic, healthcare, and behavioral models. They formed a sequence of health profiles in the form of a four-pole barycentric model of balanced, composite dimensions. It was found that developed countries dominate according to the integrated value of the four dimensions. It indicates their significant economic, social, and medical opportunities for the population. According to the balance of dimension pairs, behavioral determinants influence the imbalance for developed countries, the health care determinants - for new industrial states. The pair of socio-economic development is the most critical for developing and the least developed countries. According to the resilience level, such countries as Ireland, Luxembourg, Iceland, Switzerland, Denmark, Greece, Australia were identified. As a result, Norway's health profile was found to be the most effective four-pole barycentric model with composite dimension efficiency, dimension pair balance, and stability level. 
DOI: $10.14254 / 2071-$

789X.2021/14-3/17

JEL Classification: C02, I12, I15

Keywords: behavioral determinants, center of mass, economic determinants, healthcare determinants, model, social determinants

\section{Introduction}

The global COVID-19 pandemic has posed significant challenges to society in its unwillingness to confront them in terms of providing quality medical services and in economic, social, political, and other aspects. It is not the first mass disease that humanity has experienced since its inception, for example, as the Spanish flu pandemic (1918-1920), cholera (1852-1860), and the Black Death plague (1346-1353), etc. In today's world, this situation has shown how the imbalance of one area has negatively affected others in the country and the world by increasing its burden - the health sector. Therefore, while counteracting global problems and developing effective tools to combat them in terms of ensuring the high quality of the country's medical sector, it is also necessary to consider its economic and social development conditions, and behavioral determinants, which today prevail in a given society and create the preconditions for complicating the situation caused by the global pandemic.

Undoubtedly, the quality of healthcare in any country depends on its economy, which enables it to invest significant resources in the construction of new hospitals, training highly qualified personnel, research and development of new medicines, etc. Accordingly, a healthier population forms the most effective stratum of the able-bodied society, significantly affecting economic development. Economically developed countries provide higher social standards in society, which consider obtaining quality medical care. Weak social protection can be a trigger for economic instability and growing dissatisfaction with healthcare quality. One should also note that in this chain, it is necessary to consider the behavioral model of society, formed under the influence of its economic, social, and medical development to a greater extent, which can create a barrier for it. These are behavioral determinants such as alcohol, drugs, tobacco, unhealthy food, unprotected sex, quantitative and qualitative malnutrition, leading to diabetes, tuberculosis, HIV, anemia, obesity, increased suicidal ideation, nervous diseases, etc.

According to the World Health Organization, in 2019, the direct cause of death of 1.5 million people was diabetes. The number of those who had the disease in 2014 amounted to 422 million people, which exceeded this figure in 1980 approximately four times (108 million people) (World Health Organization, 2021a). Every year, 8 million people die from tobacco use, with $80 \%$ of those who use it regularly living in low- and middle-income countries (World Health Organization, 2021b). The World Health Organization estimates that in 2020, approximately 37.7 million people were infected with HIV and 680,000 died from the disease (World Health Organization, 2021c). 5.3\% of the total death toll in the world each year are those who regularly drink alcohol (World Health Organization, 2021d). One of the causes of cardiovascular disease is obesity, which is a problem for more than 1.9 billion adults over 18 (according to 2016) (World Health Organization, 2021e). These determinants form the profile of an unhealthy nation unable to withstand many challenges, particularly the COVID-19 pandemic. Thus, $10.5 \%$ of deaths due to coronavirus suffered from cardiovascular disease, $7.3 \%$ from diabetes, and only $0.9 \%$ did not have chronic illnesses (Minfin, 2021a). That is why there is a need to determine the existing preconditions for the countrys readiness to combat and prevent mass diseases and the necessity to reform the medical sector. 
The purpose of this study is to determine the level of the balance of social, economic, behavioral, and quality determinants of healthcare as composite targets, typical of any country in the world, to form a sustainable health profile of its population. It will outline the government's state policy directions on setting priorities for public health, reforming the medical sector, developing economic and social incentives and responding to the challenges of a society that generate such global problems as the global COVID-19 pandemic.

\section{Literature review}

The consequences of the COVID-19 pandemic have triggered large-scale global socioeconomic imbalances caused by mass disease and quarantine measures. Significant negative changes have taken place in the world economy (Tommaso, 2020), consumption (Minchenko \& Demchuk, 2021), insurance (Hinrichs \& Bundtzen, 2021), the green bond market (Keliuotytè-Staniulènienè \& Daunaravičiūtè, 2021), and business in general (Antonyuk, 2021; Tiutiunyk et al., 2021), healthcare (Androniceanu, 2020), the banking sector (Bernardelli et al., 2021), etc. That is why there is a need for a systematic restructuring of approaches to ensure the countries' readiness to combat and prevent mass diseases (Al-Naser \& Hamdan, 2021; Dutta et al., 2020; Bilan et al., 2019). In this context, the study by researchers of determinants of the impact on the country's health profile formation is a priority. Thus, the country's social sphere affects measures to combat mass diseases and depends on developing social capital, social infrastructure and social security system (Vasilyeva et al., 2020). The regional peculiarities of the population are the most significant factors, which make it more vulnerable to COVID-19 (Kuzmenko et al., 2020). A matrix of determinants was formed to study the trajectory of transformational directions of the country's economic and social development due to the pandemic Covid-19 by Vasilyeva et al., in 2021. The most informative indicators were for countries with a convergent socio-economic trend (Vasylieva et al., 2020; Bondarenko et al., 2020). It is also necessary to consider the multilevel measurement of socio-economic determinants (Druzhynina et al., 2018; Kyrychenko et al., 2018) and the existing relationship (Halaskova \& Bednar, 2020; Luchko, 2019; Pupavac et al., 2020). Antosova et al. (2019) and Baranowski \& Jabkowski (2021) identify indicators depending on household income clusters. The trend of economic growth, population health and environmental indicators are directly related to the consequences of blocking the pandemic (Smiianov et al., 2020a; Letunovska et al., 2021; Petrushenko et al., 2020). That is why it is necessary to coordinate them when assessing their impact on the formation of the health profile of the population (Stukalo et al., 2020). The possibilities of generalized indicators enable to measure the problem. Thus, of primary empirical indicators are the most effective (Kuc-Czarnecka, 2019). A key determinant of healthcare quality Smiianov et. al. (2020b) is the supply and demand of qualified occupational medicine professionals. Wysocka \& Lewandowski (2017) and Gallo et al. (2019) emphasize the managerial qualities of medical staff at the medical institutions. Mohsen et al. (2018) determine the interdependence between the cost of services and the customer satisfaction level. Gavurova et al. (2021) investigated that its long-term effectiveness depends on the organization of the public procurement system. Such measures as compliance with sanitary and hygienic standards can be an investment in improving the country's population health (Ray, 2021). Gavurova et al. (2020) identified a population index, an intensive care unit transfer rate, a long-term hospitalization rate, a mortality rate, and a mortality rate from surgery as indicators of the medical sector quality and the impact on patient satisfaction. Railaite \& C Ciutienè (2020) believe that healthcare costs have the greatest impact on the health component of human capital and, consequently, on the country's health as a whole. Chen \& Sun (2021) investigate the health of business ecosystems and identify such determinants as the dominant capabilities of the 
enterprise platform, the potential for collaboration of an additional enterprise, products and services, the sector environment. Behavioral models have an impact on various aspects of society. Didenko et al. (2020) focus on behavioral determinants and their dependence on the social security level but consider them concerning the financial sphere. Vveinhardt \& Sroka (2021) define behavioral factors as socially responsible and view them within the activities of socially responsible companies. Cismas et al. (2019) analyze the latest approaches in the economy, including economic and behavioral economics, and consider its relationship with social capital and their impact on education and public health. Undoubtedly, to prevent situations related to mass diseases, in addition to analytical measures, such preventive measures should be taken as the introduction of modern technologies in the business process management system: blockchain (Lopez et al., 2020), remote access technologies (Tovmasyan \& Minasyan, 2020), security measures (Tovmasyan \& Tovmasyan, 2020). At the same time, despite a large amount of research in this area, the country's health profile development needs further study and improvement.

\section{Methodology}

Various determinants affect the formation of the country's health profile. So, methods of scientific knowledge were used for their selection. They include analysis, synthesis, induction and deduction, which allowed to select a set of relevant indicators for each dimension. Thus, the behavioral dimension depends on people's lifestyle, traditions, financial capabilities, psychological aspects, etc., leading to serious chronic diseases and premature death in their negative form. This group included 10 factors that characterize unhealthy habits (Prevalence of current tobacco use, $\%$ of adults $\left(\mathrm{BD}_{1}\right)$, Total alcohol consumption per capita, liters of pure alcohol, projected estimates, $15+$ years of age $\left(\mathrm{BD}_{2}\right)$ ), unhealthy lifestyle (Adolescent fertility rate, births per 1,000 women ages 15-19 $\left(\mathrm{BD}_{3}\right)$, Prevalence of overweight, \% of adults $\left(\mathrm{BD}_{4}\right)$, Prevalence of undernourishment, $\%$ of population $\left(\mathrm{BD}_{5}\right)$, Suicide mortality rate, per 100,000 population $\mathrm{BD}_{6}$ )), the consequences of an unhealthy lifestyle (Incidence of tuberculosis, per 100,000 people $\left(\mathrm{BD}_{7}\right)$, Prevalence of anemia among children, $\%$ of children ages 6-59 months $\left(\mathrm{BD}_{8}\right)$, Prevalence of anemia among pregnant women, \% (BD $)$, Prevalence of HIV, total, \% of population ages 15-49 $\left.\left(\mathrm{BD}_{10}\right)\right)$. The selected determinants are indicators-destimulators, i.e., the growth of their values negatively affects the overall level, to form an integrated level of behavioral dimension. It is believed that the population, which is characterized by high values of behavioral factors, is more prone to chronic diseases, which makes it more vulnerable to a global pandemic.

The dimension of the healthcare sector quality is characterized, first of all, by those factors reflecting its state support, namely: Current health expenditure per capita, current US\$ $\left(\mathrm{HQ}_{1}\right)$ and Domestic general government health expenditure per capita, current US\$ $\left(\mathrm{HQ}_{2}\right)$ These are indicators-stimulators, the growth of which indicates an increase in the medical service quality for the population. Also, an essential feature is a factor - Medical doctors, per $10000\left(\mathrm{HQ}_{3}\right)$, which is a stimulant and shows the number of qualified medical staff per 10,000 people. Its low value indicates a low availability of medical care, which reduces the probability of the population receiving qualified care on time, especially in conditions of mass morbidity. The high quality of medical services is evidenced by the low mortality rate, for which such disincentives as Maternal mortality ratio, modeled estimate, per 100,000 live births $\left(\mathrm{HQ}_{4}\right)$, Mortality from CVD, cancer, diabetes or CRD between exact ages 30 and 70, \% ( $\mathrm{HQ}_{5}$ ), Stillbirth rate, per 1,000 total births ( $\left.\mathrm{HQ}_{6}\right)$, Tuberculosis death rate, per 100,000 people ( $\left.\mathrm{HQ}_{7}\right)$ were chosen. 
The conditions of the economic development affect the formation of the country's health profile. The higher its level, the more opportunities are for the population to receive quality medical care. Such countries are at the forefront of vaccination, introducing more effective measures to prevent mass diseases with the lowest economic consequences for the population. It means that for this dimension, three indicators-stimulators were selected (GDP per capita, current US \$ $\left(\mathrm{ED}_{1}\right)$, GDP growth, annual \% $\left(\mathrm{ED}_{2}\right)$, Ease of doing business score $\left.\left(\mathrm{ED}_{3}\right)\right)$ and one - a destimulator (Inflation, consumer prices, annual \% (ED4)). Its integrated level will show that its highest value corresponds to countries with high economic development, providing more opportunities to improve public health.

The social dimension aims to provide favorable conditions for the population, related to the improvement of spiritual and material life, which includes opportunities to provide themselves with various benefits and form a high living standard. Therefore, three stimulantindicators were selected for this area (Wage and salaried workers, \% of total employment $\left(\mathrm{SD}_{1}\right)$, Human capital index $\left(\mathrm{SD}_{2}\right)$, Life expectancy at birth, total in years $\left.\left(\mathrm{SD}_{3}\right)\right)$ and two destimulators (Unemployment, \% of the total labor force $\left(\mathrm{SD}_{4}\right)$, Refugee population by country or territory of origin $\left(\mathrm{SD}_{5}\right)$ The high value of its integrated level will indicate high social standards for the population.

A key aspect of the country's health profile modeling is to determine the balance and sustainability of social, economic, behavioral and quality determinants in the healthcare sector, using a polygon center of gravity approach. Its peaks are composite targets, i.e., those areas of human life, the balance of which is a necessary prerequisite for the country's development. A different set of determinants defines each sphere. This approach has found a practical application for the insurance and reinsurance market in the work of Kozmenko et al. (2009), where a model of their stability based on a triangle was developed. A general approach without practical implementation was proposed to analyze the business activity of companies in the article of Berzin et al. (2018). We will adapt the method of determining the center of mass to the input conditions of modeling the country's health profile.

In the first stage, the social, economic, behavioral and quality determinants of the healthcare sector are normalized. It is caused due to their different nature, represented by differences in their absolute values. The application of normalization to solve this problem will reduce the values of factors from 0 to 1 and carry out their convolution to determine the composite targets of economic, social, behavioral and quality dimensions of the medical sector.

For spatial data, it is reasonable to use the linear normalization performed by formula (1), because the observations are independent of each other and not subject to the distribution laws:

$$
\widetilde{x_{l k}}=\frac{x_{i k}-x_{\min _{i}}}{x_{\max _{i}}-x_{\min _{i}}}
$$

where $\widetilde{x_{l k}}-$ normalized input value of the factor of economic, social, behavioral and quality dimension of the healthcare sector;

$x_{i k}$ - input $i$-factor of economic, social, behavioral and quality dimension of the healthcare sector for $k$-observation of the country;

$x_{\text {min }_{i}}$ and $x_{\text {max }_{i}}$ - respectively, the minimum and maximum value of the factor of economic, social, behavioral and quality dimension of healthcare among all observations.

Formula (1) is used to stimulant variables. It is necessary to use its modification, namely normalization of Savage (2) for destimulators: 


$$
\widetilde{x_{l k}}=\frac{x_{\max _{i}}-x_{i k}}{x_{\max _{i}}-x_{\min _{i}}}
$$

In the second stage composite target indicators for each dimension - economic, social, behavioral and quality of health are calculated. Given the use of spatial data, it is proposed to calculate it using the geometric mean function (3), because it allows you to determine the average proportional value, which refers to one number as well as another number to the geometric mean:

$$
G\left(\widetilde{x_{1}}, \widetilde{x_{2}}, \ldots, \widetilde{x_{n}}\right)=\left(\prod_{i=1}^{n} \tilde{x_{l}}\right)^{1 / n}
$$

where $G\left(\widetilde{x_{1}}, \widetilde{x_{2}}, \ldots, \widetilde{x_{n}}\right)$ - geometric mean value of normalized input values of factors of economic, social, behavioral and quality measurement of the healthcare sector, which is an composite indicator;

$n$ - the number of factors in each of the dimensions.

We can use the formula of Minkowski metrics (4) for those observations that after normalization will have a value of zero, to avoid obtaining the value of the target equal to " 0 " in the case of using the geometric mean function:

$$
R\left(x_{i}\right)=1-\sqrt{\sum_{j=1}^{k} \omega_{j}\left|1-\frac{x_{i j}}{x_{\max _{j}}}\right|^{2}+\sum_{j=k+1}^{n} \omega_{j}\left|1-\frac{x_{\text {min }_{j}}}{x_{i j}}\right|^{2}}
$$

where $R\left(x_{i}\right)$ - composite indicator-target of economic, social, behavioral, and quality dimension of healthcare;

$\omega_{j}$ - the weight of each factor with which it affects the overall function. Standardized multiple regression coefficients can be used as such weights. The condition for the formation of weights is $\sum_{j=1}^{n} \omega_{j}=1$, performed if you determine the sum of standardized coefficients.

The result of the second stage will lead to four composite targets of economic, social, behavioral and quality dimensions of healthcare. Since the normalization of the initial data contributed to their reduction from 0 to 1 , the composite indicator value, which will approach 1 , will indicate the maximum value for the relevant area. Otherwise, if the value of the composite indicator approaches 0 , it will indicate that there are economic, social, or behavioral problems or in the medical field, which lead to the formation of the country's unhealthy population profile.

In the third stage, a barycentric model is built on the basis of a balance of social, economic, behavioral and quality determinants of the healthcare sector, which will have four vertices corresponding to the four selected dimensions and will be called four-pole. The algorithm for its construction is as follows:

1) the vertices of the quadrilateral are plotted on the coordinate plane, which are the values of the calculated composite targets obtained in step 2. They are connected by segments;

2) the values of the quadrilateral angles are calculated to determine the possibility of describing the circle around it. To do this, the resulting quadrilateral is divided into two triangles and the length of the sides and diagonals is determined as the length of the segments by formula (5): 


$$
A B=\sqrt{\left(x_{b}-x_{a}\right)^{2}+\left(y_{b}-y_{a}\right)^{2}},
$$

where $\mathrm{AB}$ - the length of the segment between two points $\mathrm{A}$ and $\mathrm{B}$, which are the vertices of a quadrilateral - composite indicators of four dimensions;

$\left(x_{a} ; y_{a}\right)$ - the coordinates of point $\mathrm{A}$, which correspond to the composite index of one dimension;

$\left(x_{b} ; y_{b}\right)-$ the coordinates of point $\mathrm{B}$, which correspond to the composite index of another dimension;

$3)$ calculate the values of the cosines of the angles for each of the two triangles by formula (6):

$$
\cos \alpha=\frac{b^{2}+c^{2}-a^{2}}{2 \cdot b \cdot c}
$$

where $a, b, c$ - the lengths of the three sides of the triangle, which correspond to the calculated values of the lengths of the segments determined by formula 5 . Next, the obtained values are converted into degrees;

4) sum the two angles at the bases of one triangle with the angles of the other. The sum of the obtained quadrilateral angles is checked, whether it is equal to 360 degrees. Next, opposite angles are checked whether their sum is 180 degrees. In the case of their equality, it is concluded that around this quadrilateral we can describe a circle radius of which is calculated by formula (7):

$$
R=\frac{1}{4} \sqrt{\frac{(a b+c d)(a d+b c)(a c+b d)}{(p-a)(p-b)(p-c)(p-d)}}
$$

where $a, b, c, d$-the length of the quadrilateral sides, determined by formula (7); $\mathrm{p}$ - the half-perimeter of a quadrangle, calculated as:

$$
p=\frac{a+b+c+d}{2} \text {. }
$$

The ability to describe a circle around a quadrilateral enable to draw a conclusion about the pairwise balance of dimensions. If there is a deviation of the center of mass from the reference value, this conclusion will help to analyze the problem of the dimension pairwise combination that require the development of measures considering both integrated values;

$5)$ the center of mass of the quadrilateral, its coordinates, which are calculated by formulas (9), (10) are defined:

$$
\begin{aligned}
& F_{x}=\frac{1}{6 A} \sum_{i=0}^{n-1}\left(\left(x_{i}+x_{i+1}\right)\left(x_{i} y_{i+1}-x_{i+1} y_{i}\right)\right) \\
& F_{y}=\frac{1}{6 A} \sum_{i=0}^{n-1}\left(\left(y_{i}+y_{i+1}\right)\left(x_{i} y_{i+1}-x_{i+1} y_{i}\right)\right)
\end{aligned}
$$

where $F_{x}$ and $F_{y}$-coordinates of the center of mass in the quadrilateral; 
$\left(x_{i} ; y_{i}\right),\left(x_{i+1} ; y_{i+1}\right)$ - the coordinates of the vertices of the quadrilateral, where the vertex with coordinates $\left(\mathrm{x}_{\mathrm{n}} ; \mathrm{y}_{\mathrm{n}}\right)$ will coincide with the vertex with coordinates $\left(\mathrm{x}_{0} ; \mathrm{y}_{0}\right)$;

$A$ - the area of the quadrilateral, determined by formula (11):

$$
\mathrm{A}=\frac{1}{2} \sum_{i=0}^{n-1}\left(x_{i} y_{i+1}-x_{i+1} y_{i}\right)
$$

6) a graphical visualization of the model for each country is carried out. It will allow to clearly present the country's health profile. Figure 1 shows a graphical visualization of the reference model.

The standard model (Fig. 1) is a square, the vertices of which are composite indicators determined in the second stage and correspond to four dimensions - economic, social, behavioral, and quality of the medical field. Its centroid (center of mass) is at the point of intersection of its diagonals ("Center of Mass") with coordinates $(0 ; 0)$. The vertices of the square are at points with coordinates $(1 ; 1)$ for the behavioral dimension, $(1 ;-1)$ for the economic dimension, $(-1 ;-1)$ for measuring the quality of the health care sector, $(-1 ; 1)$ for the social dimension. Their values correspond to the maximum value of the composite target, which can be achieved in the country. It means a high level of social and economic development, medical sector quality and low values of factors that form a negative behavioral model of society. The standard model corresponds to the healthiest population profile.

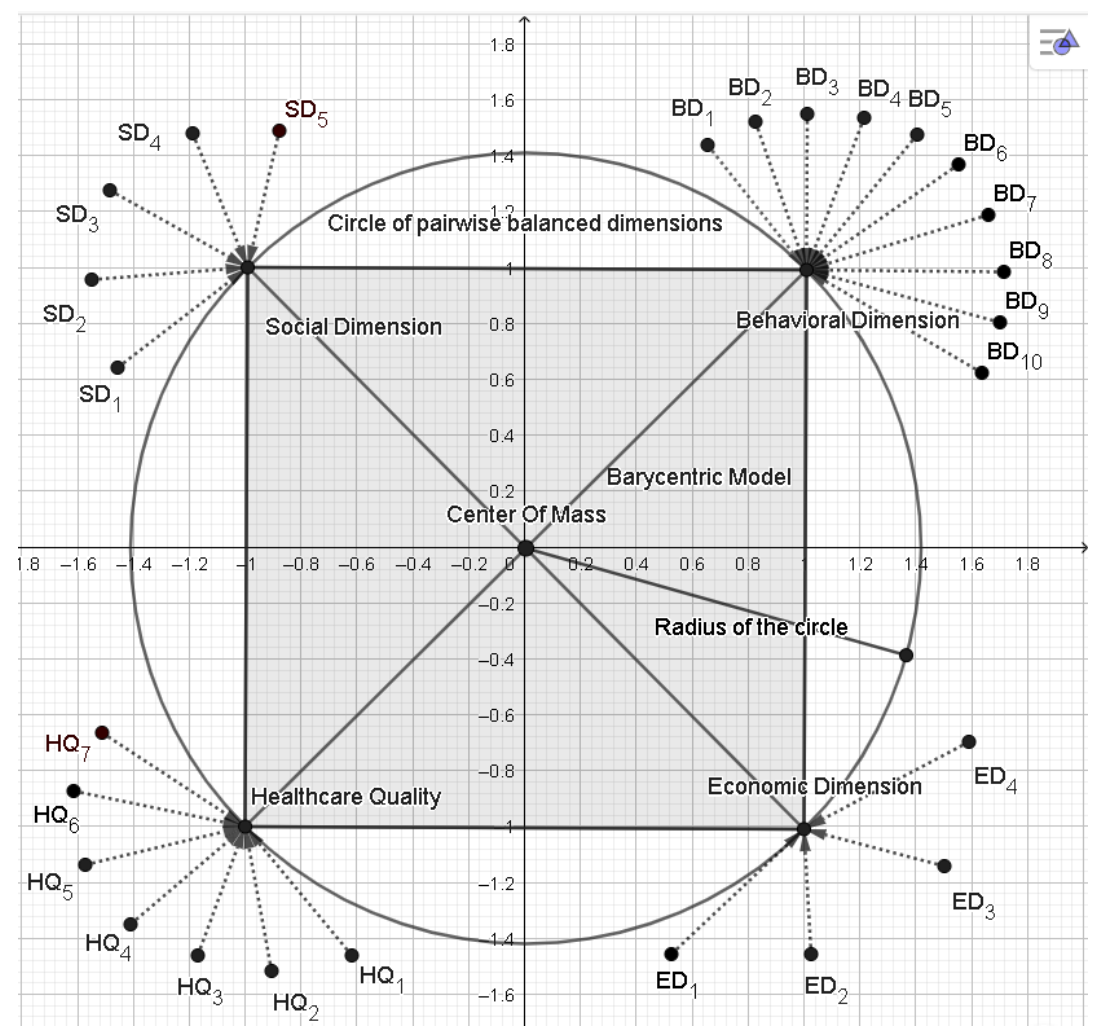

Figure 1. The standard four-pole barycentric model of the country's health profile Source: own construction.

It will be difficult to obtain a standard square in the calculation process since under such conditions, a country with such a model is essentially a super-country with the most developed economic, social, medical spheres and the absence of a negative behavioral model of society. 
The government needs to consider this model and work to develop more effective measures to bring the country's actual health profile closer to the benchmark.

In the fourth stage, the difference between the center of mass for a particular country and the center of mass for an ideal model is determined. It is calculated as the length of the segment by formula (5).

The fifth stage is an analysis of the built four-pole barycentric model of the country in relation to the country's obtained health profile and its corresponding capabilities to meet the challenges of global pandemics. We will form the rules that must be taken into account in the analysis of the results from building a barycentric model for different countries, compliance with which is a guarantee for the formation of the most effective country's health profile:

1) the coordinates of the four points - the vertices of the quadrilateral should be in the range from 0 to 1 . The closer the value to 1 , the higher the level of development provided by this dimension. The closer it is to 0 , the lower the level of dimension development;

2) a circle can be described around a quadrilateral if the sum of its opposite angles is equal to 180 degrees. In cases where the circle cannot be described, it will indicate an imbalance between the two pairs of dimensions. Their analysis will reveal the inefficiency of the respective pair and direct further actions of the government in these areas;

3) the center of mass of the barycentric model should be as close as possible to the center of mass of the standard model, indicating high stability of the barycentric model. If the center of the circle circumscribed around the quadrilateral coincides with the center of mass, then we are dealing with a square, a reference model of a country's health profile.

\section{Empirical results}

Calculations were made for empirical data from 112 countries. The values of the selected indicators of the four dimensions were taken from the database of the World Bank (The World Bank, 2021), and the indicator - Medical doctors (per 10,000) - from the database of the World Health Organization (2021f) for 2018. This period was chosen because most of the factors needed to perform health profile calculations do not have actual values after this period. As a result of the first and second stages of the methodological approach and to verify compliance with the first rule, four groups of countries were formed by the level of economic development, the integrated values of the four dimensions for the first fifteen of which are shown in Figures 2-5.

The obtained values of composite dimensions (Fig. 2-5) approach the ideal weight (up to "1") for all groups of countries but are not equal to it. In practice, it is difficult to achieve this level, so the closer the calculated values go to it, the higher the degree of development of the country's relevant dimension. It can be noted that the best result among all nations is shown by Norway, which has the highest total value of composite dimensions - economic, social, behavioral and quality of health care, which is 3.3280. Such countries as Iceland, Switzerland, Denmark, Ireland, Sweden, Luxembourg, USA, Australia, Japan, the Netherlands, Austria, Finland, Israel, the United Kingdom and others (Fig. 2) also have the highest scores, indicating high opportunities for the population of these countries to ensure a high level of its health and combat the mass diseases. 


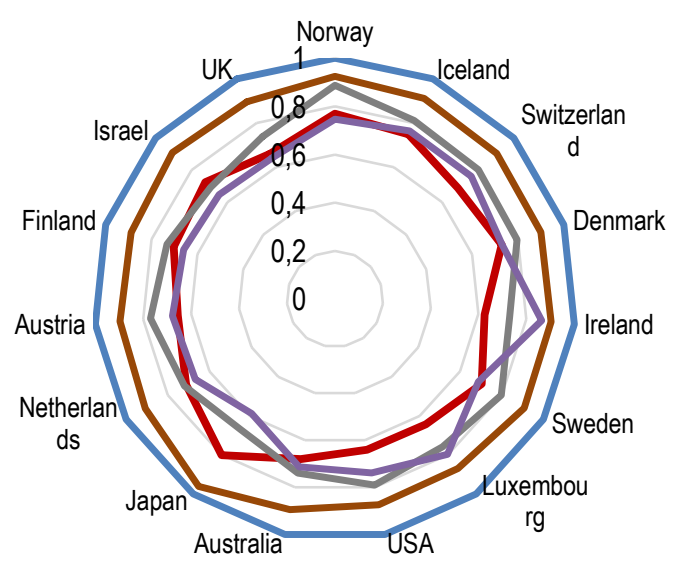

Figure 2. Composite dimensions for developed countries

Source: own construction.

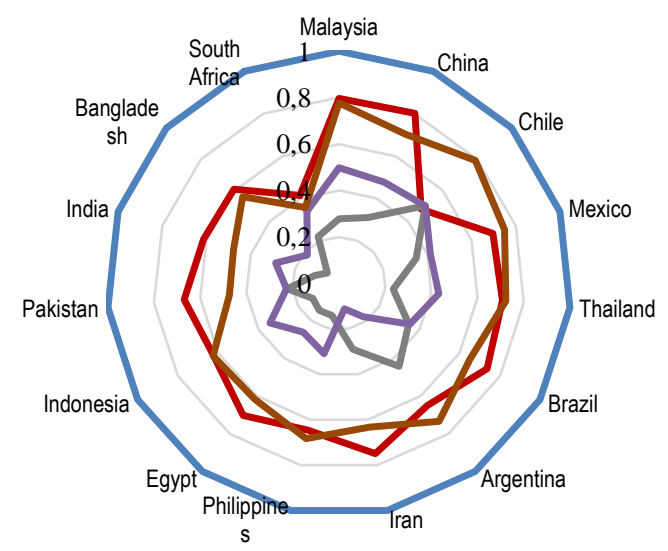

Figure 4. Composite dimensions for newly industrialized countries Source: own construction.

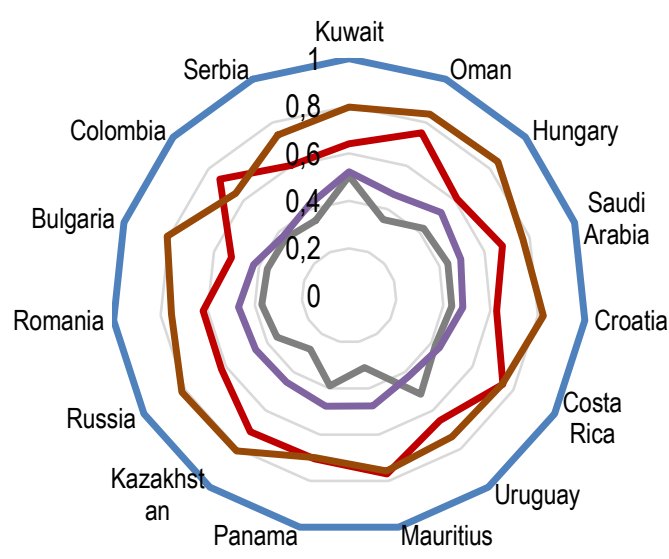

Figure 3. Composite dimensions for developing countries

Source: own construction.

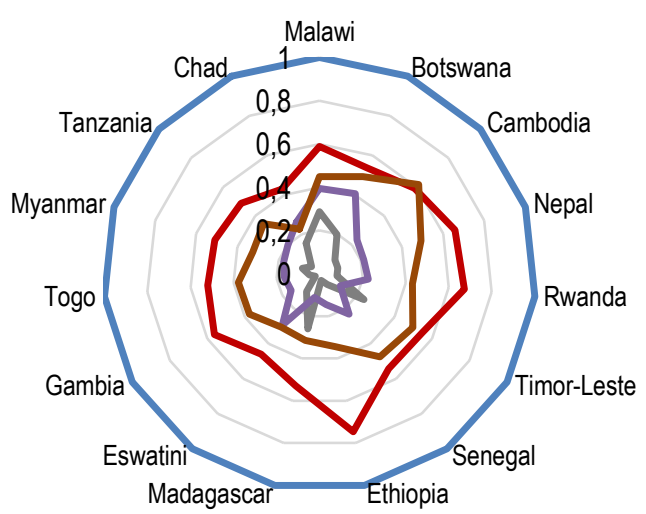

Figure 5. Composite dimensions for the least developed countries Source: own construction.

where blue line - standard value; red line - behavioral dimension; green line - social dimension; grey line - healthcare quality dimension; yellow line - economic dimension.

The prevalence of behavioral and social aspects over the economic and medical sector quality dimension is peculiar for developing countries (Fig. 3). A similar situation is typical for the newly industrialized countries (Fig. 4). In other words, to ensure the health profile of the population, these countries should pay attention to the component of improving the quality of the medical sector and economic growth because in the case of mass disease, the economy and healthcare will be primarily affected. For the least developed countries, all four dimensions are quite low (Fig. 5), which requires the government to develop a set of strategic dimensions to ensure the minimum needs of the population in the event of a pandemic since their social, economic and medical capabilities cannot provide it.

The obtained results from the degree measure of opposite angles of the quadrilateral, determined in the third stage and necessary for checking the conditions of the second rule, indicate the balancing of two pairs of dimensions. Their values should be equal to $180^{\circ}$. Figures 6-9 present histograms for developed countries, newly industrialized, developing, and least 
developed. $50 \%$ and $100 \%$ corresponds to $180^{\circ}$. If the value is less or greater than $50 \%$, it indicates that the degree of the pair of angles is less than $180^{\circ}$ or more, i.e., there will be an imbalance of the selected pairs of dimensions. A pair of economic and social development dimensions and a pair of behavioral models and quality of healthcare were chosen for the calculations. Pairwise correlation coefficients between the four dimensions were calculated to substantiate this choice. Thus, it turned out that the highest values of the correlation coefficients between the following combinations of pairs: economic dimension and health care quality dimension -0.9196 , social and behavioral -0.6552 . Using such pairs of dimensions, the barycentric model will take the form of a rhombus, which will lead to an imbalance between the pairs of composite indicators. Therefore, according to the lowest values of correlation coefficients, we choose a pair of behavioral models and quality of healthcare (0.4278) and economic and social development (0.8580).
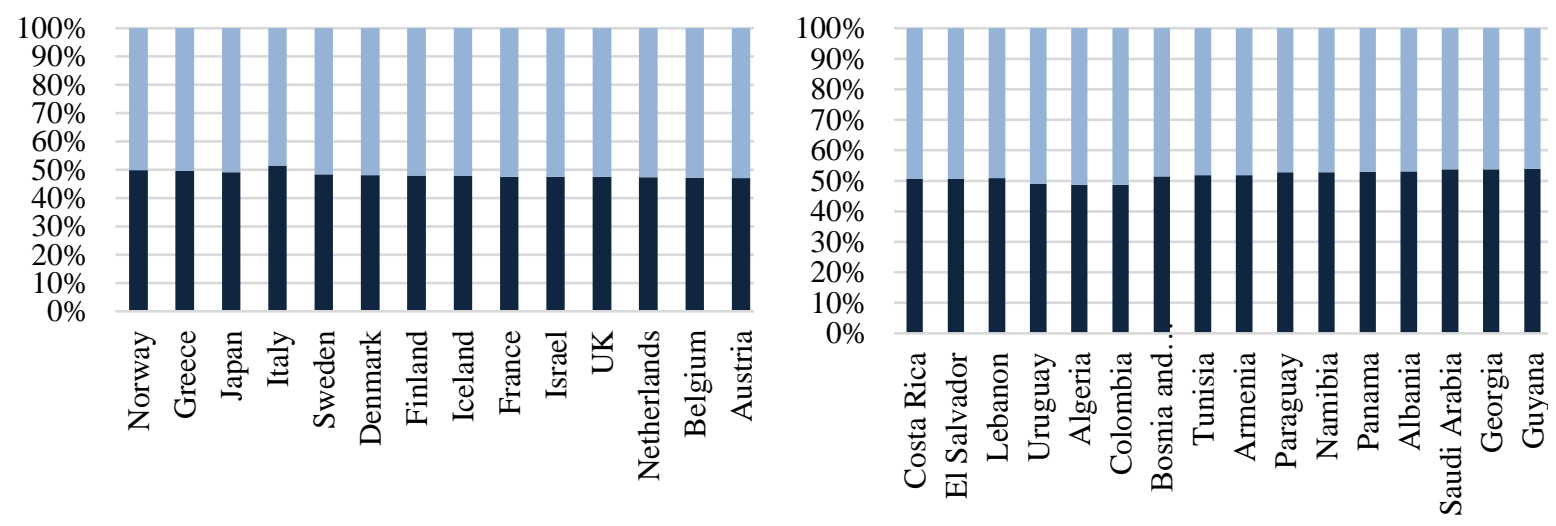

Figure 6. Balance of dimension pairs for developed countries

Source: own construction.

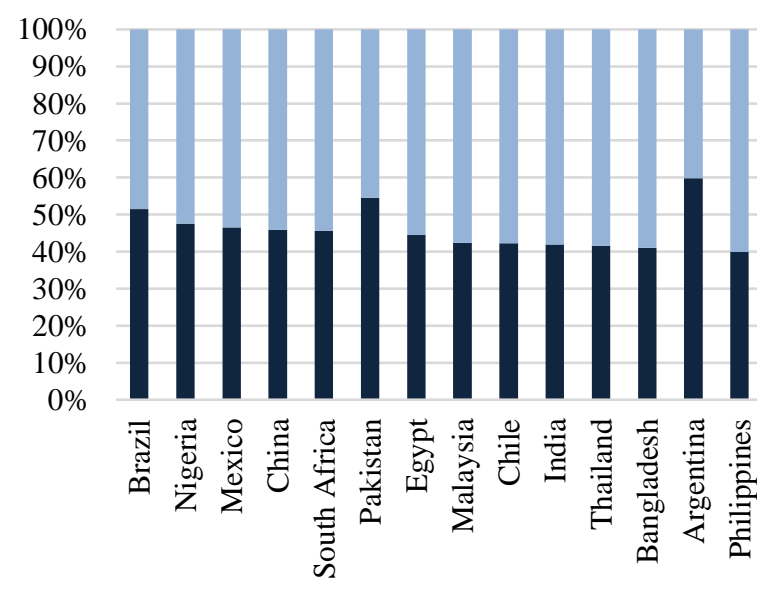

Figure 7. Balance of dimension pairs for developing countries

Source: own construction.

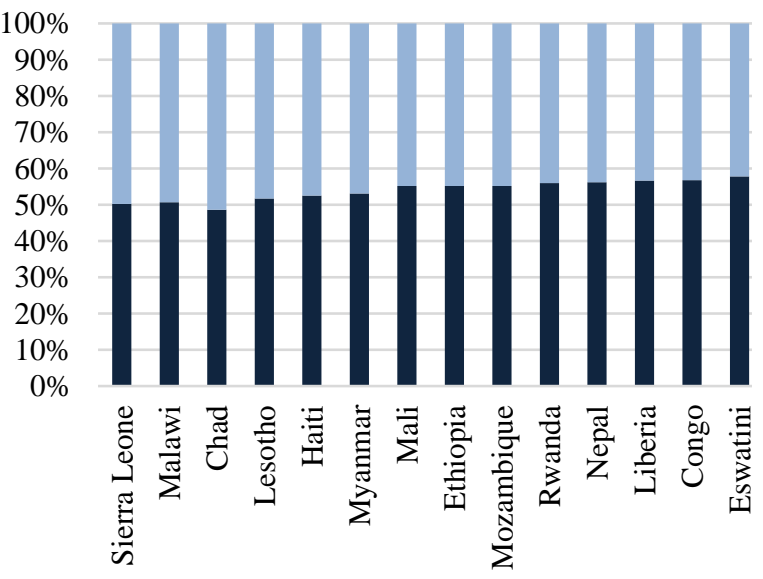

Figure 8. Balance of dimension pairs for newly industrialized countries Source: own construction.

Figure 9. Balance of dimension pairs for the least developed countries

Source: own construction.

where dark blue column - a pair of Behavioral and Healthcare Quality Dimensions; light blue column - a pair of Economic and Social Dimensions. 
The calculated values of the sums of opposite angles in the quadrilateral, which characterize the pairwise balancing of the four dimensions, show that Norway, Greece, Japan, Italy, Sweden, Denmark, Finland, Ireland are the most balanced developed countries (Fig. 6). Costa Rica and El Salvador are among the developing countries (Fig. 7), among the newly industrial - Brazil (Fig. 8), the least developed - Sierra Leone and Malawi (Fig. 9). The results show that most countries are characterized by an unbalanced formation of their health profile. For developed countries, the most unbalanced is the pair of behavioral models and healthcare quality (Fig. 6), due to the negative impact of such determinants as excessive consumption of alcohol, tobacco and obesity, and partly low levels of medical costs compared to other countries, such as Norway and the United States. The pair of behavioral patterns and healthcare quality is also unbalanced for the newly industrialized countries (Fig. 8). For these countries, the impact of factors related to the assessment of the health sector quality is more critical, especially the increased mortality from disease, the level of financial costs and the provision of qualified personnel. It is especially true for countries such as Bangladesh, India, Egypt, Nigeria and the Philippines. For developing and least developed countries, the pair of economic and social development is unbalanced. It is necessary to allocate economic factors which are key for the maintenance of a healthy way of life for many countries of these groups.

Figure 10 demonstrates the calculated value of the distances between the centers of mass for all countries. It means that the deviations of the actual values of their centers of mass from the ideal value show the country's level of stability by achieving the balance of all four dimensions - social, economic, behavioral, and healthcare. The calculations were performed at the fourth stage of the methodology to verify the condition of the third rule. The obtained value, approaching " 0 ", indicates that the conditions for effective interaction of the economy, social development, behavioral model of society and medical sector quality are formed for the population. They create the profile of a healthy country and will resist mass diseases in the future.

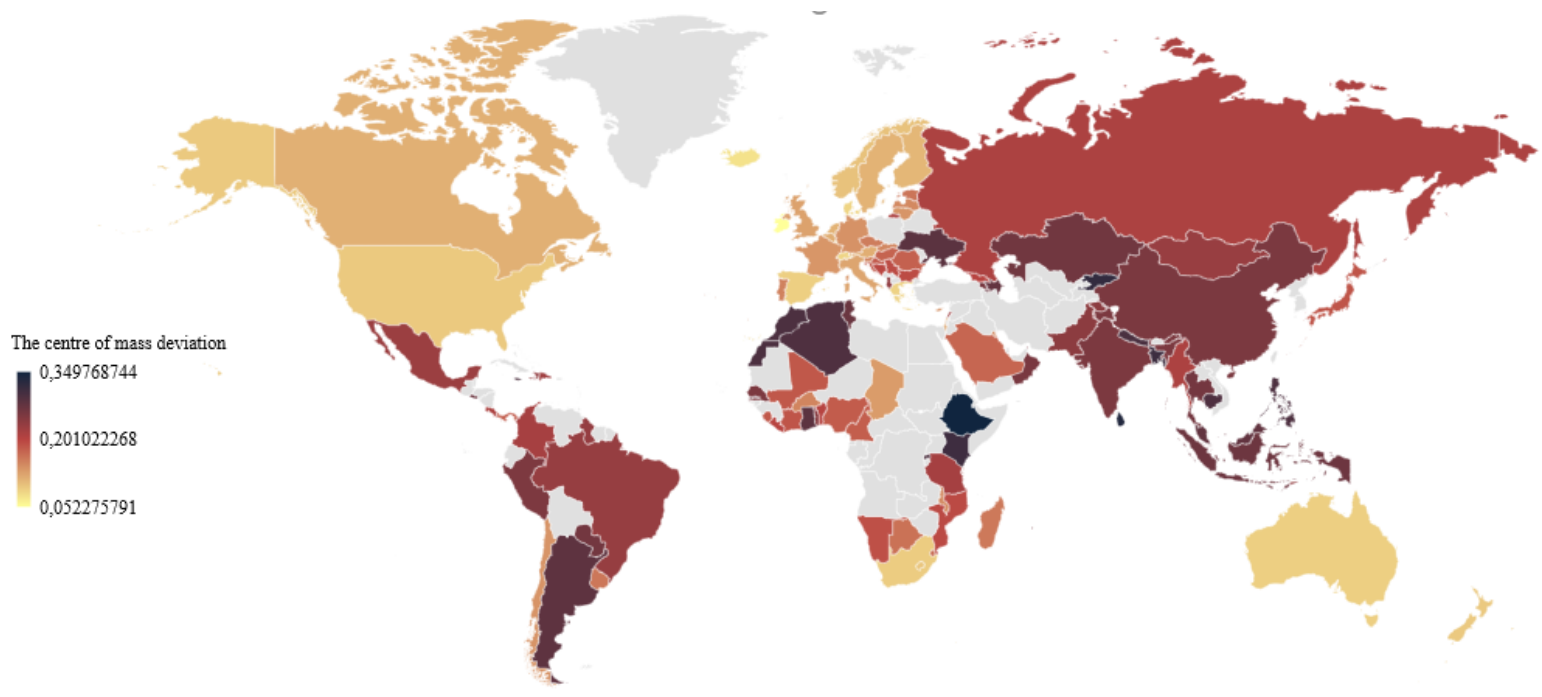

Figure 10. The level of countries' stability based on the deviation of the centers of mass of their barycentric models

Source: own construction.

Thus, the most stable countries are Ireland (0.0523), Luxembourg (0.0654), Iceland (0.0753), Switzerland (0.0854), Denmark (0.0856), Greece (0.0880), Australia (0.0903), Spain (0.0904), South Africa (0.0927), New Zealand (0.0953), the United States (0.0956), Lesotho 
(0.0973), Norway (0.1006). Most of these states are developed, but the calculations revealed that developing and least developed countries can also be sustainable. This factor indicates that, regardless of the values of the targets, the country has an effective combination of them, which can act as a driver for their further dynamic development to form a health profile of the country. The least stable countries were Ethiopia (0.3498), Sri Lanka (0.3329), Iran (0.3277), the Kyrgyz Republic (0.3200), Egypt (0.3123), Bangladesh (0.3099), Kenya (0, 3097), Nepal (0.2984), Morocco (0.2974), Jamaica (0.2968).

The results show that these countries have an imbalance in the formation of their health profile due to the predominance of mainly one or two areas over others. It indicates the inconsistency of their development and the need for their transformation. According to the calculations, at all stages of the methodology and the conditions of three rules of construction and barycentric model analysis, the most effective health profile of the country is the model of Norway (Fig. 11).

The obtained Norway four-pole barycentric model demonstrates high values of four composite dimensions - economic (0.7466), social (0.9245), behavioral (0.7694) and medical industry quality (0.8874). The pairwise combination of dimensions is quite balanced, as evidenced by the ability to outline a circle around the quadrilateral. The deviation of the calculated center of mass from the reference is equal to 0.1006 , indicating the approximation of Norway's barycentric model's stability to the reference level.

For comparison, we will form the health profile of the most stable country - Ireland, and unstable - Ethiopia (Fig. 12-13).

The Ireland's four-pole barycentric model (Fig. 12) shows a relatively high value of composite dimensions - economic (0.8635), social (0.9030), behavioral (0.6255) and the medical industry quality (0.7291). The pairwise combination of composite dimensions is not balanced, as evidenced by the impossibility of delineating a circle around a quadrilateral. The pair of behavioral patterns and the quality of the healthcare sector is the most critical, where behavioral determinants, i.e., the levels of alcohol, tobacco and obesity consumption, are more unbalanced. The deviation of the center of mass of the Irish model from the reference value is 0.0523 , which is the best value among all other countries. Despite the imbalance of pairwise dimensions, their combination allows creating appropriate economic, social and medical conditions for the population, enabling conditions for improving its health level. The Ethiopian model (Fig. 13) demonstrates low values of composite dimensions - economic (0.1461), social (0.3434) and medical sector quality (0.0311). The behavioral dimension is equal to 0.7463 , indicating a lower tendency of the Ethiopian population to lead an unhealthy lifestyle than the population of some European countries. The low level of economic development and the healthcare quality is an essential factor in reducing the population's ability to receive qualified medical care in case of a pandemic and to obtain financial guarantees in case of a lockdown. The model demonstrates the lack of balance between the dimension pairs and the largest difference in the distance between the country's center of mass and its reference value. 


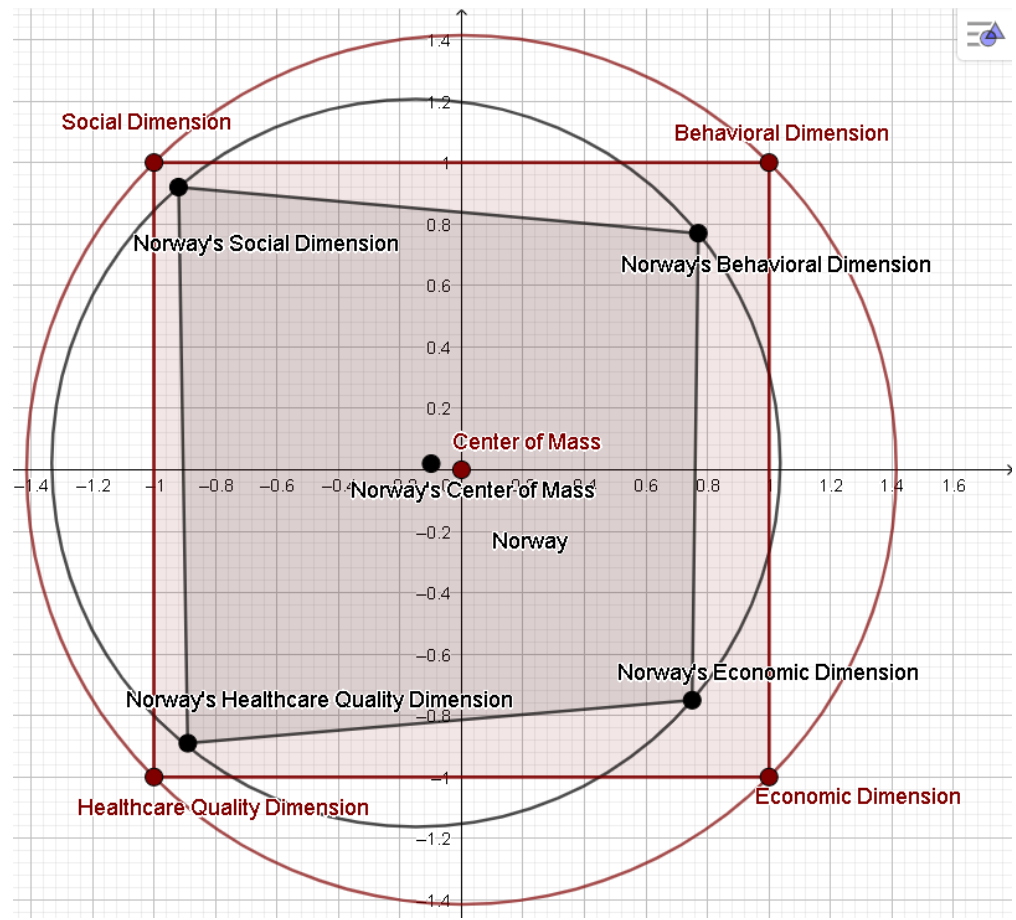

Figure 11. Norway's health profile based on a four-pole barycentric model Source: own construction.

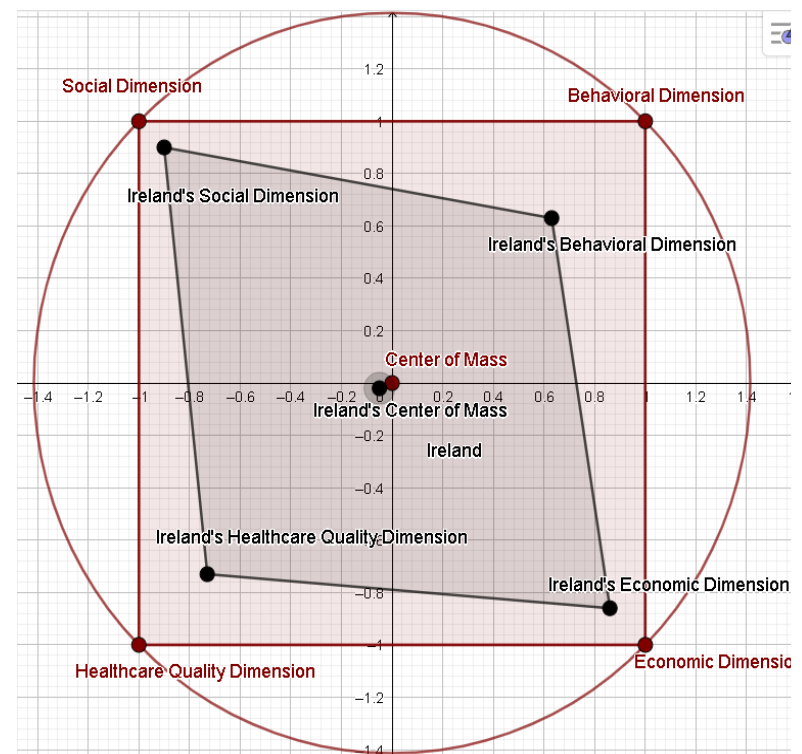

Figure 12. Ireland's health profile Source: own construction.

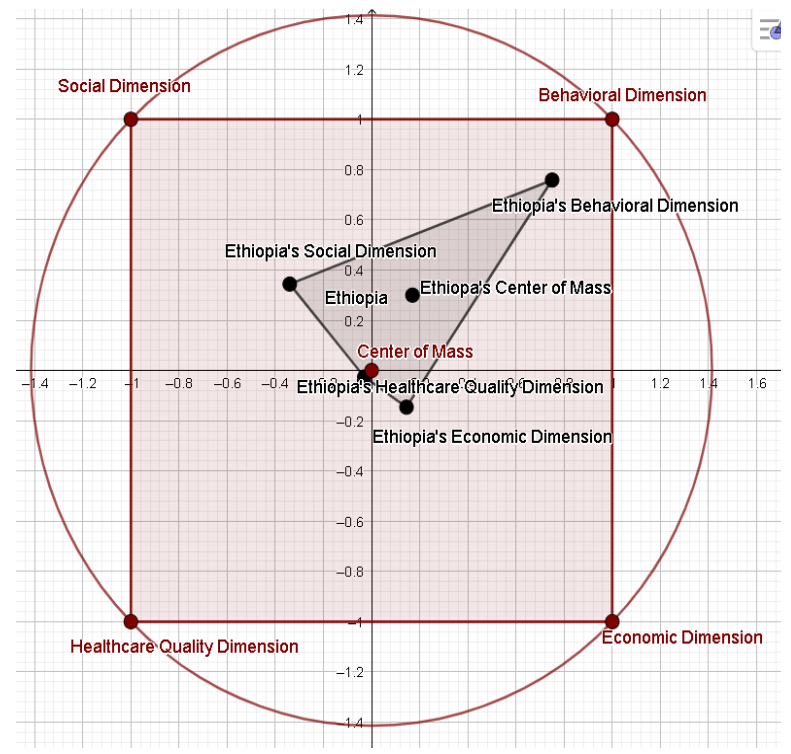

Figure 13. Ethiopian's health profile Source: own construction. 


\section{Conclusion}

The global COVID-19 pandemic has shown humanity its unwillingness to respond quickly, fight systematically, and combat such phenomena. That is why today, the problem of providing the countries' population with appropriate conditions for preserving and improving their health is of a great importance. These should be measures to overcome the effects of mass diseases and systematic steps to identify various determinants that may directly or indirectly affect this process. In this study, the authors use the approach of determining the center of mass to shape the country's health profile as a tool for preliminary analysis and identification of weaknesses that may be the reason for the country's inability to address global issues such as pandemics. The health profile is a four-pole barycentric model formed based on composite dimensions that characterize the behavioral aspect of the population, the level of medical industry quality in the country, and the economic and social development conditions. The dimensions and determinants that form them were chosen based on the analysis of the literature and the basis of the use of scientific knowledge methods. Three main rules were identified to apply the method, which provide for the construction of the model and its analysis by the values of each composite dimension, the balance of dimension pairs and the value of the distance of the calculated center of mass from the standard. Calculations were performed for data from 112 countries. It was found that developed countries have integrated values of four dimensions higher than for other groups (developing countries, newly industrialized and least developed). It indicates more excellent economic, social, medical opportunities for these countries to ensure a high level of health. The calculated sums of opposite angles of the four-pole barycentric model showed that the pair of behavioral dimension and quality of the medical field, especially behavioral determinants is the most unbalanced for developed countries. This pair is also unbalanced for the newly industrialized countries, but mainly in terms of quality assurance in the health sector.

For developing countries and the least developed, the pair of economic and social dimensions upsets the balance of the model, especially in terms of economic development. They were determining the stability level of the model based on assessing the deviation of the calculated center of mass from the standard allowed to identify such countries as Ireland, Luxembourg, Iceland, Switzerland, Denmark, Greece, Australia, Spain, South Africa, New Zealand, USA, Lesotho, Norway. The analysis of the results based on the conditions of three rules determined that the health profile of the Norwegian population was the most effective. Its model demonstrates the highest values of composite indicators of economic, social, behavioral and health quality, full balance of dimension pairs and close to reference calculated value of the center of mass. The experience of this country should be considered by others in developing strategies aimed at improving the living standards of the population. The paper also presents the health profiles of Ireland and Ethiopia, which have the best and worst stability values of barycentric models, respectively. The relevant government commissions and organizations the activities of which aim to improve the medical service quality and ensure the fight against mass diseases to solve the problematic aspects based on the country's health profile, should consider the obtained results.

\section{Acknowledgement}

The work was performed within the framework of basic funding of the Ministry of Education and Science of Ukraine, order dated 16.04.2021 № 434, Contract BF/24-2021. 


\section{References}

Androniceanu, A. (2020). Major structural changes in the EU policies due to the problems and risks caused by COVID-19. Administratie si Management Public, 34, 137-149. doi:10.24818/amp/2020.34-08

Al-Naser, M., \& Hamdan, A. (2021). The impact of public governance on the economic growth: Evidence from gulf cooperation council countries. Economics and Sociology, 14(2), 85110. doi:10.14254/2071-789X.2021/14-2/5.

Antonyuk, N., Plikus, I., \& Jammal, M. (2021). Sustainable business development vision under the covid-19 pandemic. Health Economics and Management Review, 2(1), 37-43. doi: 10.21272/hem.2021.1-04.

Antosova, I., Hazuchova, N., \& Stakova, J. (2019). Market Segmentation in Healthcare. Marketing and Management of Innovations, 3, 151-166. doi: 10.21272/mmi.2019.3-12.

Baranowski, M., \& Jabkowski, P. (2021). Basic income support in Europe: A cross-national analysis based on the European Social Survey Round 8. Economics and Sociology, 14(2), 167-183. doi: 10.14254/2071-789X.2021/14-2/9.

Bernardelli, M., Korzeb, Z., \& Niedziółka, P. (2021). The banking sector as the ab-sorber of the COVID-19 crisis' economic consequences: perception of WSE investors. Oeconomia Copernicana, 12(2), 335-374. doi: 10.24136/oc.2021.012.

Bilan, Y., Vasilyeva, T., Kryklii, O., \& Shilimbetova, G. (2019). The creative industry as a factor in the development of the economy: Dissemination of european experience in the countries with economies in transition. [Kūrybinè industrija kaip ekonomikos plètros veiksnys: Europietiškosios patirties sklaida pereinamojo laikotarpio ekonomikos šalyse] Creativity Studies, 12(1), 75-101. doi: 10.3846/cs.2019.7453.

Bondarenko, A., Zakharkina, L., Syhyda, L., \& Saher, L. (2020). The economic and marketing attractiveness of countries: Measurement and positioning in terms of economic security. International Journal of Sustainable Development and Planning, 15(4), 439-449. doi: 10.18280/ijsdp.150404.

Cismas, L. M., Miculescu, A., Negrut, L., Negrut, V., Otil, M. D., \& Vadasan, I. (2019). Social Capital, Social Responsibility, Economic Behavior and Sustainable Economic Development - An Analysis of Romania's Situation. Transformations in Business \& Economics, 18, 2A(47A), 605-628. Retrieved from: http://www.transformations.knf.vu.lt/47a/article/soci (26.02.2021).

Chen, Y., \& Sun, Y. (2021). Determinants of platform ecosystem health: an exploration based on grounded theory. Journal of Business Economics and Management, 22(5), 1142-1159. doi: $10.3846 /$ jbem.2021.15047.

Didenko, I., Paucz-Olszewska, J., Lyeonov, S. \& Ostrowska-Dankiewicz, A. (2020). Social safety and behavioral aspects of populations financial inclusion: A multicountry analysis. Journal of International Studies, 13(2), 347-359. doi: 10.14254/2071-8330.2020/13-2/23.

Druzhynina, V., Likhonosova, G., \& Lutsenko, G. (2018). Assessment welfare of the population in the synergetic system of socio-economic exclusion. Marketing and Management of Innovations, 2, 54-68. doi: 10.21272/mmi.2018.2-05.

Dutta, P., Dutta, U., Hasan, S., Sarkar, S., Sana, T. (2020). Educate, Empower And Protect People Through Timely Authentic Information: Explore How Bangladeshi Newspapers Response To COVID-19 Pandemic. SocioEconomic Challenges, 4(3), 93-103. doi: 10.21272/sec.4(3).93-103.2020.

Gallo, P., Mihalcova, B., Vegsoova, O., Dzurov-Vargova, T \& Busova, N. (2019). Innovative Trends in Human Resources Management: Evidence for the Health Care System. Marketing and Management of Innovations, 2, 11-20. doi: 10.21272/mmi.2019.2-01. 
Gavurova, B., Belas, J., Rowland, Z., \& Kubak, M. (2021). The impact of agreement on government procurement use on the competition in Slovak healthcare sector. Administratie si Management Public, 36, 102-115. doi: 10.24818/amp/2021.36-06.

Gavurova, B., Kovac, V., \& Khouri, S. (2020). Purpose of Patient Satisfaction for Efficient Management of Healthcare Provision. Polish Journal of Management Studies, 22 (1), 134-146. doi: 10.17512/pjms.2020.22.1.09.

Halaskova, R., \& Bednar, P. (2020). Relationship of social protection expenditures and socioeconomic indicators: A panel data analysis of the EU countries. Montenegrin Journal of Economics, 16(2), 191-31. doi: 10.14254/1800-5845/2020.16-2.2.

Hinrichs, G., \& Bundtzen, H. (2021). Impact of COVID-19 on personal insurance sales Evidence from Germany. Financial Markets, Institutions and Risks, 5(1), 80-86. doi: 10.21272/fmir.5(1).80-86.2021.

Hudáková, M., \& Masár, M. (2018). The assessment of key business risks for SMEs in Slovakia and their comparison with other EU countries. Entrepreneurial Business and Economics Review, 6(4), 145-160. https://doi.org/10.15678/EBER.2018.060408

Keliuotytè-Staniulènienè, G., \& Daunaravičiūtè, K. (2021). The global green bond market in the face of the COVID-19 pandemic. Financial Markets, Institutions and Risks, 5(1), 5060. doi: 10.21272/fmir.5(1).50-60.2021.

Kozmenko, O., Merenkova, O., \& Boyko, A. (2009). The analysis of insurance market structure and dynamics in Ukraine, Russia and European Insurance and Reinsurance Federation (CEA) member states. Problems and Perspectives in Management, 7(1), 29-39. Retrieved from: $\quad$ https://www.businessperspectives.org/index.php/journals/problems-andperspectives-in-management/issue-24/the-analysis-of-insurance-market-structure-anddynamics-in-ukraine-russia-and-european-insurance-and-reinsurance-federation-ceamember-states (26.02.2021).

Kuc-Czarnecka, M. (2019). Sensitivity analysis as a tool to optimise Human Development Index. Equilibrium. Quarterly Journal of Economics and Economic Policy, 14(3), 425440. doi: 10.24136/eq.2019.020.

Kuzmenko, O., Vasylieva, T., Vojtovič, S., Chygryn, O., \& Snieška, V. (2020). Why do regions differ in vulnerability to covid-19? spatial nonlinear modeling of social and economic patterns. Economics and Sociology, 13(4), 318-340. doi:10.14254/2071-789X.2020/13$4 / 20$

Kyrychenko, K. I., Samusevych, Y. V., Liulova, L. Y., \& Bagmet, K. (2018). Innovations in country's social development level estimation. Marketing and Management of Innovations, 2, 113-128. doi: 10.21272/mmi.2018.2-10.

Letunovska, N., Lyuolyov, O., Pimonenko, T., \& Aleksandrov, V. (2021). Environmental management and social marketing: A bibliometric analysis. Paper presented at the E3S Web of Conferences, 234. doi: 10.1051/e3sconf/202123400008.

Lopez, B., \& Alcaide, A. (2020). Blockchain, AI and IoT to improve governance, financial management and control of crisis: Case Study COVID-19. SocioEconomic Challenges, 4(2), 78-89. doi: 10.21272/sec.4(2).78-89.2020.

Luchko, M., Lew, G., Ruska, R., \& Vovk, I. (2019). Modelling the optimal size of investment portfolio in a non-state pension fund. Journal of International Studies, 12(1), 239-252. doi:10.14254/2071-8330.2019/12-1/16

Minchenko, M., \& Demchuk, K. (2021). Pandemic consequences and crisis recovery scenarios. Health Economics and Management Review, 2(1), 67-75. doi: 10.21272/hem.2021.1-07.

Minfin (2021). Smertnost ot koronavirusa: Demografiya i riski| [Mortality from coronavirus: demographics

and risks].

Retrieved

from: 
https://index.minfin.com.ua/reference/coronavirus/demography/

$(26.02 .2021)$

[in Russian].

Mohsen, Yo., Hussein, H., Mahrous, A. (2018). Perceived service value, customer engagement and brand loyalty in health care centres in Egypt. Marketing and Management of Innovations, 3, 85-108. doi: 10.21272/mmi.2018.3-08.

Petrushenko, Y., Vadym, A., Vorontsova, A., \& Ponomarenko, O. (2020). Sustainable development goals as a tool for strategic planning in communities: A bibliometric analysis of research. Paper presented at the E3S Web of Conferences, 202. doi:10.1051/e3sconf/202020203005.

Pupavac, D., Delibasic, M., Pupavac, J., \& Stremikis, J. (2020). Interdependence of quality of life and happiness of the population in Southeast European countries. Montenegrin Journal of Economics, 16(4), 7-15. doi: 10.14254/1800-5845/2020.16-4.1.

Ray, A. (2021). Containing Airborne Transmission of COVID-19 and its implications for global economic recovery. Business Ethics and Leadership, 5(1), 81-88. doi:10.21272/bel.5(1).81-88.2021.

Railaite, R., \& Čiutienè, R. (2020). the impact of public health expenditure on health component of human capital. Engineering Economics, 31(3), 371-379. doi:10.5755/j01.ee.31.3.25158.

Smiianov, V. A., Lyulyov, O. V., Pimonenko, T. V., Andrushchenko, T. A., Sova, S., \& Grechkovskaya, N. V. (2020a). The impact of the pandemic lockdown on air pollution, health and economic growth: system dynamics analysis. Wiadomosci Lekarskie (Warsaw, Poland : 1960), 73(11), 2332-2338. Retrieved from: https://wiadlek.pl/wpcontent/uploads/archive/2020/WLek202011102.pdf.

Smiianov, V. A., Vasilyeva, T. A., Chygryn, O. Y., Rubanov, P. M., \& Mayboroda, T. M. (2020b). Socio-economic patterns of labor market functioning in the public health: challenges connected with Covid-19. Wiadomosci Lekarskie (Warsaw, Poland : 1960), 73(10), 2181-2187. Retrieved from: https://wiadlek.pl/wpcontent/uploads/archive/2020/WLek202010114.pdf.

Stukalo, N., Lytvyn, M., Petrushenko, Y., \& Omelchenko, Y. (2020). The achievement of the country's sustainable development in the conditions of global threats. Paper presented at the E3S Web of Conferences, 211. doi: 10.1051/e3sconf/202021101029.

The World Bank (2021). Indicators. Retrieved from: https://data.worldbank.org/indicator (26.02.2021).

Tiutiunyk, I., Humenna, Yu., \& Flaumer, A. (2021). Covid-19 impact on business sector activity in the EU countries: digital issues. Health Economics and Management Review, 2(1), 54-66. doi: 10.21272/hem.2021.1-06.

Tommaso, F. D. (2020). The New Italian Legislation on Corporate Governance and Business Crisis. The Impact of Covid - 19 on SMEs and the Recent Rules to Mitigate the Effects. Financial Markets, Institutions and Risks, 4(4), 91-108. doi: 10.21272/fmir.4(4).91108.2020.

Tovmasyan, G., \& Minasyan, D. (2020). The Impact of Motivation on Work Efficiency for Both Employers and Employees also During COVID-19 Pandemic: Case Study from Armenia. Business Ethics and Leadership, 4(3), 25-35. doi:10.21272/bel.4(3).2535.2020 .

Tovmasyan, G., \& Tovmasyan, R. (2020). Tourism Safety And Security In The Republic Of Armenia. SocioEconomic Challenges, 4(2), 14-22. doi:10.21272/sec.4(2).14-22.2020.

Vasilyeva, T., Bilan, S., Bagmet, K., \& Seliga, R. (2020). Institutional development gap in the social sector: Crosscountry analysis. Economics and Sociology, 13(1), 271-294. doi:10.14254/2071-789X.2020/13-1/17. 
Vasilyeva, T., Kuzmenko, O., Kuryłowicz, M., \& Letunovska, N. (2021). Neural network modeling of the economic and social development trajectory transformation due to quarantine restrictions during covid-19. Economics and Sociology, 14(2), 313-330. doi: 10.14254/2071-789X.2021/14-2/17.

Vasylieva, T., Machová, V., Vysochyna, A., Podgórska, J., \& Samusevych, Y. (2020). Setting up architecture for environmental tax system under certain socioeconomic conditions. Journal of International Studies, 13(4), 273-285. doi: 10.14254/2071-8330.2020/13-4/19.

Vveinhardt, J., \& Sroka, W. (2021). Independent Variables Affecting Employee Behaviour in Socially Responsible Organisations: Working Environment in Lithuania and Poland. Engineering Economics, 32(3), 266-277. doi: 0.5755/j01.ee.32.3.28651.

Wysocka, M., \& Lewandowski, R. (2017). Key Competences of a Health Care Manager. Journal of Intercultural Management, 9(4), 165-184. doi: 10.1515/joim-2017-0026.

World Health Organization (2021a). Diabetes. Retrieved from: https://www.who.int/newsroom/fact-sheets/detail/diabetes (26.02.2021).

World Health Organization (2021b). Tobacco. Retrieved from: https://www.who.int/newsroom/fact-sheets/detail/tobacco (26.02.2021).

World Health Organization (2021c). HIV/AIDS. Retrieved from: https://www.who.int/newsroom/fact-sheets/detail/hiv-aids. (26.02.2021).

World Health Organization (2021d). Alcohol. Retrieved from: https://www.who.int/newsroom/fact-sheets/detail/alcohol (26.02.2021).

World Health Organization (2021e). Obesity and overweight. Retrieved from: https://www.who.int/news-room/fact-sheets/detail/obesity-and-overweight (26.02.2021).

World Health Organization (2021f). Medical doctors (per 10000). Retrieved from: https://www.who.int/data/gho/data/indicators/indicator-details/GHO/medical-doctors(per-10-000-population) (26.02.2021).

Yarovenko, H. (2021). Information Security as a Driver of National Economic Development. (Doctoral dissertation). Retrieved from SumDU Repository: https://essuir.sumdu.edu.ua/handle/123456789/83664 (26.02.2021) [in Ukrainian]. 